\title{
THE TECHNIQUE OF BUTLIN'S OPERATION OF MARGINAL RESECTION OF THE TONGUE.
}

\author{
By SAMPSON HANDLEY, LoNDON.
}

THE object of the present short paper is to draw attention to a method originated by the late Sir H. T. Butlin, of treating by operation cases(a) Where the tongue is originally, or has become, too large for the mouth; (b) Where its lateral margin in contact with the teeth shows dangerous or annoying irritability.

The effects of the operation are: (I) The size of the tongue is reduced without altering its shape, impairing its mobility, or interfering with speech; (2) The teeth, instead of being in contact with an irritable papilla-bearing surface, now lie in contact with smooth mucous membrane derived from the inframarginal surface of the tongue. Moreover, owing to the reduced size of the tongue, the contact between it and the teeth is less intimate.

The operation is not of recent origin. It was practised by $\operatorname{Sir} H$. T. Butlin for a number of years. I believe, however, that it is less widely known than its merits deserve, perhaps because its author preferred to exercise the scalpel more often than the pen. Indeed, he had not troubled to christen his offspring, for which I venture to suggest the name "marginal resection of the tongue."

The notes of the case which drew my attention to this method are as follows :

Case I.-Miss A. G., aged 36, was sent to me in February, Igr 1 , by her medical man on account of the condition of her tongue, a condition which had been present since childhood, but was only definitely noticed by the patient at the age of seventeen. It gave her no trouble until 1907. At that time she began to have attacks of soreness in it, lasting perhaps a week, and recurring every three or four months. These attacks have increased in frequency and severity, and the tongue is now a source of constant discomfort to her. Her teeth are in good condition and do not appear to be causing irritation. The only noticeable fact in the history is that for twelve years past she has been subject to attacks of abdominal pain, unrelated to food, associated with vomiting, lasting perhaps half an hour and occurring at irregular intervals. For the last four years these attacks have been almost in abeyance. The bowels are habitually somewhat loose. There is no evidence of syphilis.

On examination, the tongue is obviously too large for the mouth, and is deeply marked by the teeth. The dorsum of the tongue is covered by closely-set foliated papillary eminences, separated by deep grooves and indentations, and this condition is most marked towards the margin. The whole tongue is sore, more especially at its edges, but is not ulcerated. She finds that vaseline temporarily relieves the soreness. Rough or pungent articles of diet, such as curry or toast, do not seem to aggravate the condition, nor does singing, which she practises constantly.

Believing that the condition was one of papillary hypertrophy, probably depending on congenital lymphatic obstruction, I told her that, in my opinion, some form of plastic operation to reduce the size of the tongue would be advisable, especially since various applications had failed, and since her pleasure in life was seriously interfered with. 


\section{MARGINAL RESECTION OF THE TONGUE}

I thought of resecting a wedge from the tip of the tongue and taking out lateral wedges from the margins opposite the molar teeth; but before doing anything I asked the patient to consult Sir H. T. Butlin and obtain his advice. He counselled the operation of marginal resection in the following letter:-

“March 28, I9Ir.

"Many thanks for your note with Miss G-. I cannot cure her any more than you could. Nor do I know what that condition is due to. I have seen several cases precisely similar, but I have never been able to work out their history or how they arose. I scarcely think they can be due to congenital defect, because there is an absence of papiliæ in the fissures, and papillæ occur right down to the bottom of true physiological fissures. Also, she never noticed the fissures till she was about seventeen, when she appears to have found them. Again, they associate with some enlargement of the end of the tongue, so that it becomes indented by the teeth, and sore from rubbing. There is more induration of that part of the tongue than there is in the plicated tongues.
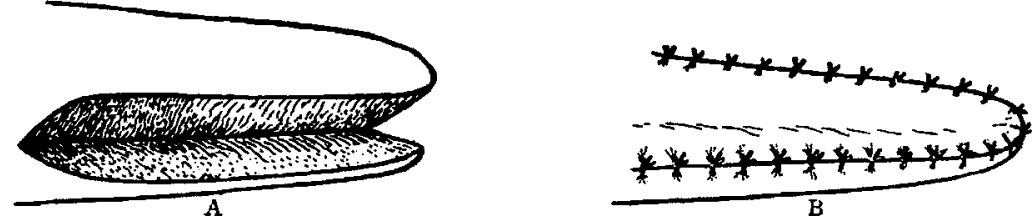

FtG. II,-Marginal Resection of the Tongue.

Butlin's otiginal diagram of the operation. (Burghard's System of Operative Surgery.)

" It has been suggested that this condition depends on previous circulus migrans of the tongue (the pathology of which has not been discovered). But I have not been able to trace any connection. There is the possibility of S.- contracted, not hereditary, because there are no signs of H.S.--but contracted from a nurse or some other person in infancy. But there are no gummata, and no actual ulcers.

"I have given Miss G- toilet lanolin instead of vaseline, but $I$ have told her that she had better ask you (when she has tried the lanolin for a little while) to trim the tongue and remould it for her. If you have not done it, you will find the description and figures in my article in Burghard's recent book. If you do a preliminary laryngotomy (not tracheotomy), you can operate at your leisure and with practically no danger to the patient."

The operation was performed by a somewhat modified technique which I devised to prevent hæmorrhage and to avoid recourse to laryngotomy.

One object of the present paper is to state this technique precisely, since in my opinion it makes the operation much simpler and safer.

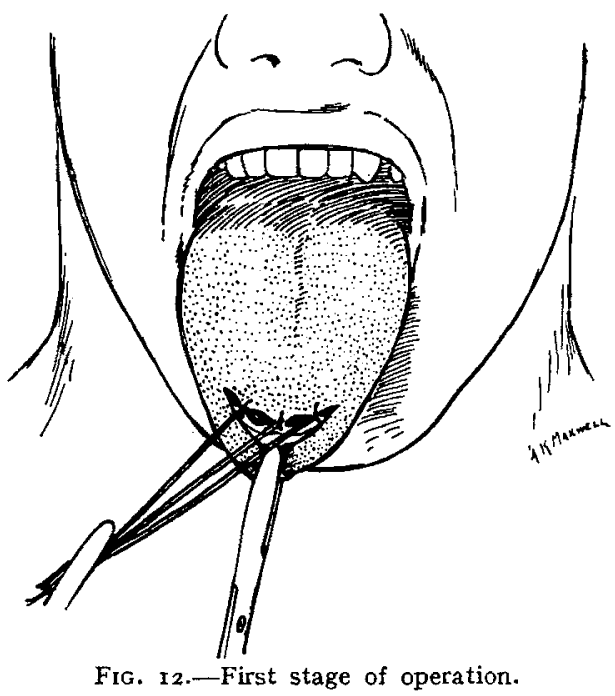
Figs. 12 to I $_{5}$ will help to make the explanation clear.

The patient being anæsthetized, the tongue is transfixed far back by a stout 


\section{THE BRITISH JOURNAL OF SURGERY}

silk ligature which serves to control it. The excision of the wedge is commenced at the tip of the tongue, and involves at first two converging incisions about an inch and a half in length (Fig. I2). Before anything further is done, sutures are introduced. The effect is that bleeding is stopped, and the tongue can now be

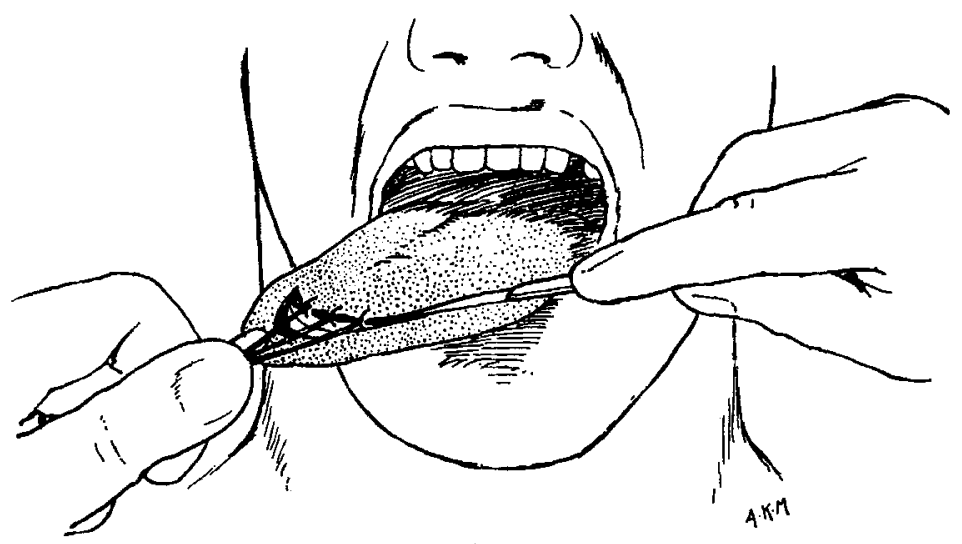

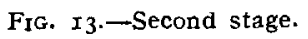

manipulated by a loop of tissue, shortly to be removed, but still attached at both ends like the handle of a hand-bag. Making traction on this handle, a further portion of the marginal wedge, perhaps an inch long, is now cut along the margin of the tongue, and again stitches are introduced. The same

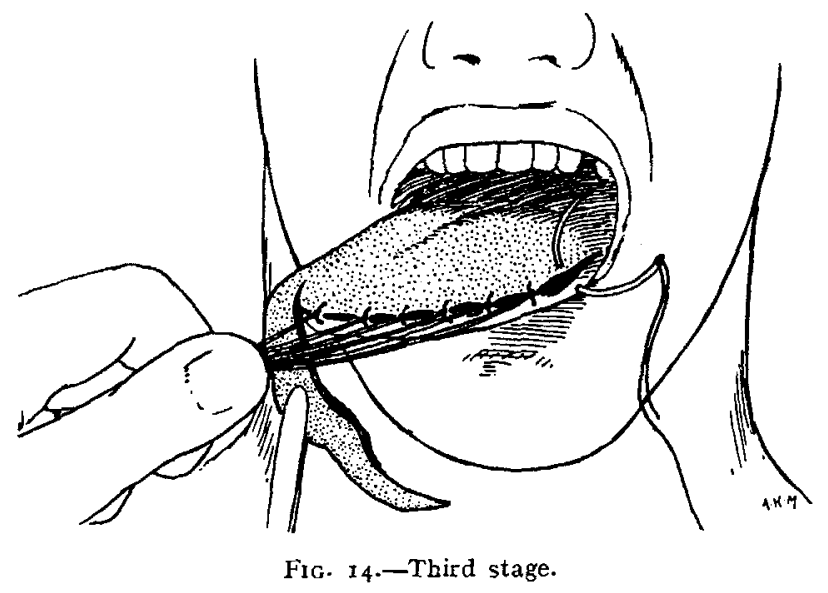

manœuvre is carried out on the opposite side of the tongue, and is repeated until the wedge has been cut and the sutures have been placed right back to the last molar tooth. When this point has been reached, the $V$-shaped notch cut in the tongue is made more and more shallow, until the posterior end of the wedge is freed entirely on either side, and comes away. Operating in this way, hæmorrhage 
is reduced to a minimum. The tongue is easily controlled throughout, and laryngotomy becomes unnecessary.

In excising the wedge, the lower of the two incisions accurately follows the junction between the rough mucosa of the dorsum and the smooth mucosa of the inframarginal portion of the tongue. Thus none of the latter is sacrificed, and the strip of mucosa removed is derived entirely from the dorsum. The teeth now lie in contact with smooth inframarginal mucosa, and do not touch the papilla-bearing portion of the tongue.

The skilful administration of the anæsthetic is a very important point in the operation, for the patient's coughing reflex should not be abolished. In this respect I am much indebted to Dr. C. V. Martin, anæsthetist to the Bolingbroke Hospital, who administered the anæsthetic in Case 1.

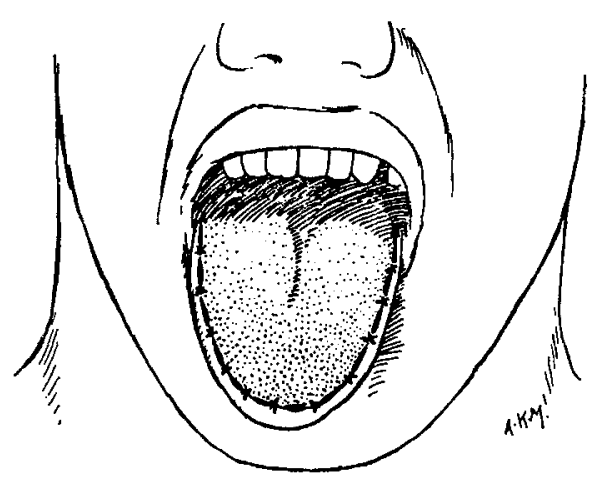

FIG. 15.-The operation completed.

The incision in the tongue rapidly healed, the stitches were removed on the fifth day, and the patient left the hospital on the eighth day feeling quite comfortable. She was seen again in June, IgII. The tongue was of normal size, scarcely marked by the teeth, and the papillary condition of the dorsum

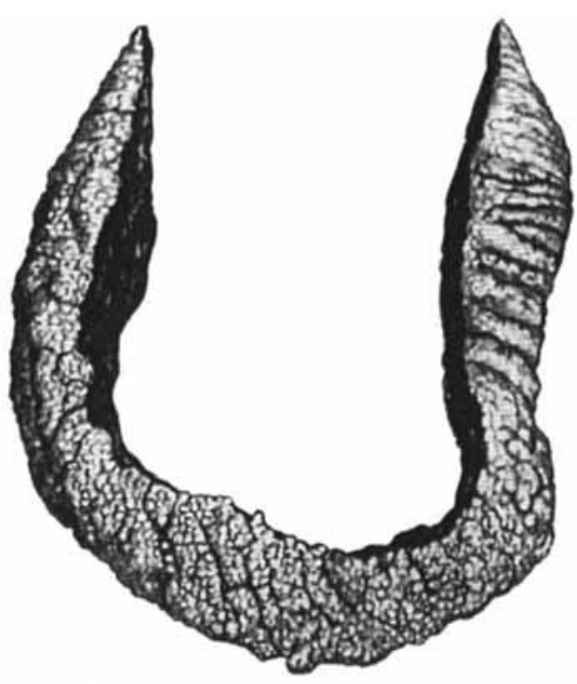

FIG. I6.-Case I. The strip of tongue removed (natural size). had certainly subsided. The soreness had completely disappeared, and the only thing of which she complained was an occasional twinge of sharp pain in the tongue. As a rule she is entirely oblivious of the existence of the tongue, and she is delighted with the result. The scar of the resection can only be seen with difficulty. The patient states that she has lost a lisp which characterized her speech, but a trace of this still remains.

This patient was again seen recently (Jan., Igr3) and her tongue was photographed (Fig. I7). She still remains perfectly comfortable. A microscopic section of the portion of tongue removed failed to throw light on the cause of the papillary and general hypertrophy.

Opportunities for the practice of marginal resection are few, for its possibilities are not generally known, but in a second case, recently, I have again performed the operation with most satisfactory results. In this instance only a unilateral operation was required. 
Case 2.-.-Miss E. B., a lady of middle age, was sent to me on January 2, I9I3. by Dr. J. B. Mason, of Ealing. Four years ago she first noticed that her tongue was very sore on the left side, and a little white mark appeared along the left margin. The soreness grew progressively worse, and about May, rg Io, she first sought medical advice. Since that time she has had varied treatments, without lasting benefit. In May, Igıo, she saw a lady physician, who applied picric acid to the affected area, and prescribed injections of a non-autogenic vaccine and a tonic containing arsenic.

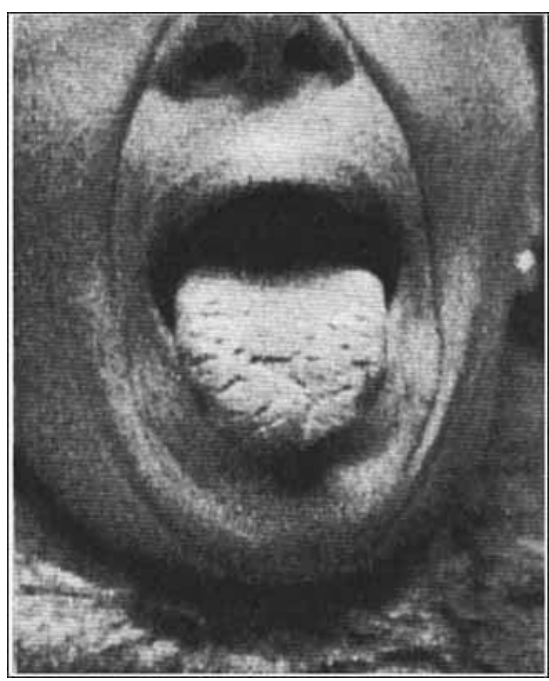

Fra. I7.-Case r. The tongue about a year after operation. Note the papillary hyper. trophy, with deep sulci, mostly transverse. Later in 1910, she saw a well-known lady surgeon, who considered that the condition might be a nevus and advised the use of electrolysis. At other times $x$-rays were admintstered to the tongue, and in I9I 2 zinc ionization was given with some benefit by Dr. Mason. In June, I9I2, she saw another surgeon, who at first considered the condition might be tuberculous. He painted it once with a strong acid, the nature of which the patient did not know. In July, I912, another physician painted the area with 30 per cent chromic acid, once a day for a time, and then two or three times a week with the same acid in $4^{\circ}$ per cent strength. Altogether this treatment lasted for a month without any improvement taking place. In September, 1912, a mixture of salvarsan and glycerin was prescribed by Dr. Mason to be rubbed on the tongue, and this treatment produced temporary relief. In October, I912, a surgeon suggested and carried out the application of the actual cautery. The cauterized area healed up after five weeks and the tongue looked better, but there was no subjective improvement. Orthoform was at one time applied to the tongue, and the patient once took iodide for a long time without benefit. The teeth have also recerved careful attention. The patient formerly wore an upper plate, but has not done so for eighteen months. The persistence with which the patient has tried various treatments seems to prove conclusively that the soreness had been severe, and a source of chronic misery.

On examination of the tongue I found on the left side a whitish area, devoid of papillæ, extending from near the tip to the foremost circumvallate papilla, its lower edge corresponding to the margin of the tongue, while its upper edge showed a fairly sharply-marked line situated on the dorsum. At its widest part the area measured about an inch from side to side. On the right side of the tongue, although here the patient complained of no soreness, a similar but smaller bare area was found.

Since the futility of local applications had been conclusively proved, I advised unilateral marginal resection on the left side. This was done at Ealing, with Dr. Mason's assistance, about January I0, I9I3, Mr. Apperly giving the anæsthetic. The technique used was that already described in this paper, and practically no blood obtained access to the pharynx. The stitches were removed about the sixth day.

At the beginning of February, Dr. Mason reported to me that the patient had entirely lost the soreness of which she complained, that her articulation remained good, and that the tongue was soundly healed. There had been no 
return of symptoms up to the present, though the patient complains of an occasional twinge in the region of the scar. She says she feels that her tongue " inhabits a palace," a phrase which expresses very well the sensation of space, and freedom resulting from the diminution in the size of the tongue and the absence of irritating contact between the excised tender area and the left alveolar margin. I saw this patient recently and was well satisfied with the result. The scar can only be seen with difficulty.

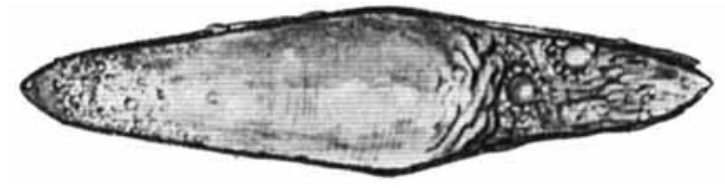

FIG. I 8.-The strip of tongue removed in Case 2 (unilateral marginal resection). Note the circumvallate papilla visible near the posterior end of the strip.

It appears likely that marginal resection may find its widest field of service in selected cases of chronic glossitis of syphilitic origin. It removes that particular area of the tongue which is known to be the seat of election for carcinoma, and moreover, by reducing its size, it removes the tongue from contact with the teeth. Butlin considered that the operation of marginal resection is specially appropriate to syphilitic cases. I may here quote his remarks upon this subject :

For many years past I have operated on cases of chronic superficial affections of the tongue which have resisted treatment, and in which ulcers, fissures, and tender areas have formed again and again, or where thick and threatening areas of leucoplakia have formed. Experience of the earlier cases has enabled me to hold out much more definite promise of success than I could do in the first cases of the kind. But operation is not applicable to all cases. Some of them are so extensive that they would necessitate removal of a large part of the tongue, of the floor of the mouth, of the gums, and of the inside of the cheeks. So far as the tongue is concerned, the most favourable cases are those in which the disease is limited to the dorsum, or to the borders and tip. The cases are better suited to operation if the under surface of the tongue is not affected, as the mucous membrane can then be employed in the remoulding of the tongue.

A prejudice exists against operations on persons whose tongues exhibit signs of past or recurring syphilis, lest the wound should refuse to heal and become syphilitic. I have many times operated on such tongues. Provided the incisions be carried through the unaffected portions of the tongue, the patients seem to recover as well as any other patients, and none of the wounds have become syphilitic ulcers. Even in those cases in which the incisions have been carried through parts which have been the seat of past syphilitic lesions, I have seen no mischief, provided the disease be not progressive and the parts be soundly healed. The prejudice against operations on such tongues does not therefore seem to be justified.

In those cases in which the borders only are affected, incisions are carried round the tip and borders so as to enclose the whole area of the disease and to meet at their posterior ends on each side. They are carried well into the substance of the tongue, so as to enclose a wedge-shaped piece of muscle. The edges are approximated. These operations are very successful. The removal of the borders and tip in the manner which has just been described results merely in diminishing the size of the fore-part of the tongue, and does not interfere with speech. It is very desirable, in such cases, not to leave a projection at the point on each border where the incisions meet, since such projections are apt to be irritated or even caught between the teeth and bitten. ${ }^{1}$ 


\section{THE BRITISH JOURNAL OF SURGERY}

I have written this brief paper as a tribute of respect, and because I believe the operation of marginal resection is little known. Performed by the technique I have suggested, it is practically free from the risk of hæmorrhage and its attendant lung complications. Its more general employment would doubtless diminish appreciably the frequency of tongue-cancer.

I.am sure the readers of this journal will feel indebted to me for reproducing the letter given on p. 43. Written in haste and in a period of declining health, it reveals the writer perhaps the more clearly for its lack of literary pretension. Up to his latest days Butlin lived on the edge of knowledge, seeking truth there in the surrounding darkness, ready always to assist another's search. Above all, he never permitted ignorance, whether in himself or others, to masquerade as knowledge, and he always stated the facts in few and plain words.

REFERENCE.

${ }^{1}$ BuRGHARD's System of Operative Surgery, ii, 209. 